\footnotetext{
JURNAL CEMERLANG: Pengabdian pada Masyarakat

P-ISSN 2654-4741 / E-ISSN 2655-7894

Vol. 3, No. 1, Desember 2020, 29 - 37

DOI: https://doi.org/10.31540/jpm.v3i1.859

PENERBIT: LP4MK STKIP PGRI LUBUKLINGGAU
}

\title{
PELATIHAN ANALISIS DATA UJI COBA INSTRUMEN \\ DENGAN MENGGUNAKAN PROGRAM SPSS VERSI 22
}

\author{
Isbandiyah, Yeni Asmara \\ STKIP PGRI Lubuklinggau, Indonesia \\ Email: isbandiyah@stkippgri-lubuklinggau.ac.id
}

\begin{abstract}
ABSTRAK
Tujuan Pengabdian Kepada Masyarakat ini yaitu: (1) mahasiswa dapat memahami analisis uji coba instrumen melalui pelatihan dengan menggunakan SPSS Versi 22; dan (2) agar mahasiswa dapat mengoperasikan program SPSS Versi 22 sebagai alat untuk menganalisis data uji coba instrumen. Adapun metode yang digunakan dalam kegiatan pengabdian ini yaitu dengan menggunakan metode ceramah, tanya jawab, dan demonstrasi. Untuk sasaran kegiatan dalam pengabdian ini adalah seluruh mahasiswa program studi Pendidikan Sejarah yang akan menyusun skripsi. Berdasarkan hasil kegiatan Pengabdian Kepada Masyarakat, maka secara keseluruhan peserta kegiatan dapat memahami tentang analisis data uji coba instrumen serta mampu mengoperasikan program SPSS Versi 22, dengan jumlah persentase sebesar $80 \%$, kehadiran peserta dengan jumlah persentase $58 \%$ dari jumlah yang diharapkan, serta antusiaseme neserta dalam mengikuti kegiatan nelatihan dikatakan baik.
\end{abstract}

ABSTRACK

The Objectives of Community Service are: (1) students can understand the instrument trial analysis through training using SPSS Version 22; and (2) so students can operate the SPSS Version 22 program as a tool to analyze instrument trial data. The method used in this service is to use the lecture, question and answer, and demonstration methods. For the purpose of the activities in this service are all History Education study program students who will prepare their thesis. Based on the results of Community Service activities, overall activity participants can understand the instrument trial data analysis and be able to operate the SPSS Version 22 program, with a percentage of $80 \%$, attendance at a percentage of $58 \%$ of the expected amount, and enthusiasm of the participants in participating in training activities it is said to be good.

KEYWORDS

pengabdian, analisis uji coba instrumen, SPSS

service, instrument trial analysis, SPSS
ARTICLE HISTORY

Received 09 February 2020

Revised 15 Desember 2020

Accepted 29 Desember 2020

CORRESPONDENCE Isbandiyah @ isbandiyah@stkippgri-lubuklinggau.ac.id 


\section{JURNAL CEMERLANG: Pengabdian pada Masyarakat \\ P-ISSN 2654-4741 / E-ISSN 2655-7894 \\ Vol. 3, No. 1, Desember 2020, 29 - 37 \\ DOI: https://doi.org/10.31540/jpm.v3i1.859 \\ PENERBIT: LP4MK STKIP PGRI LUBUKLINGGAU}

\section{PENDAHULUAN}

Adapun latar belakang permasalahan diadakan kegiatan Pengabdian Kepada Masyarakat adalah agar dapat meningkatkan peran dan partisipasi STKIP-PGRI Lubuklinggau dalam membangun kesejahteraan masyarakat dari hasil-hasil penelitian STKIP-PGRI Lubuklinggau, sehingga dapat dimanfaatkan untuk memperkuat daya saing industri nasional, dan menyelesaikan permasalahan yang terjadi di industri maupun permasalahan di masyarakat umum. Selanjutnya dapat dijadikan sebagai alternatif solusi berdasarkan kajian akademik terhadap kebutuhan, tantangan, atau persoalan yang dihadapi masyarakat, baik secara langsung maupun tidak langsung.

Berkaitan dengan kajian akademik, maka salah satu permasalahan yang dihadapi oleh mahasiswa, khususnya pada Program Studi Pendidikan Sejarah STKIP-PGRI Lubuklinggau adalah belum diaplikasikannya program SPSS dalam analisis data instrumen penelitian. Bagi para mahasiswa yang akan menghadapi penyusunan skripsi selalu dibingungkan oleh perhitungan statistik. Hal ini dirasakan oleh sebagian besar mahasiswa Program Studi Pendidikan Sejarah, khususnya semester VIII.

Skripsi merupakan salah satu mata kuliah yang wajib ditempuh oleh mahasiswa pada semester akhir. Meskipun hanya berbobot 4 sks, tetapi penyususnan skripsi bisa menghabiskan waktu hingga empat semester. Biasanya yang menjadi permasalahan bagi mahasiswa dalam penyususan skripsi adalah cara menghitung atau menganalisis data-data yang telah diperoleh pada penelitian. Khususnya, bagi mahasiswa yang mengambil jenis penelitian pendidikan.

Selama ini, dalam teknik analisis data penelitian, mahasiswa di Program Studi Pendidikan Sejarah STKIP-PGRI Lubuklinggau selalu menggunakan analisis statistik dengan cara manual yang sering diterapkan oleh ilmu-ilmu alam, padahal untuk pengolahan data dalam ilmu-ilmu sosial sudah diperkalkan sejak lama program analisis statistik yang sesuai dengan ilmu-ilmu sosial, yaitu program SPSS. Hal ini didukung oleh pernyataan salah satu dosen Program Studi 


\section{JURNAL CEMERLANG: Pengabdian pada Masyarakat \\ P-ISSN 2654-4741 / E-ISSN 2655-7894 \\ Vol. 3, No. 1, Desember 2020, 29 - 37 \\ DOI: https://doi.org/10.31540/jpm.v3i1.859 \\ PENERBIT: LP4MK STKIP PGRI LUBUKLINGGAU}

Pendidikan Sejarah yaitu Ibu Ira Miyarni Sustianingsih, S.Pd., M.Hum., yang menjelaskan bahwa "analisis data instrumen dalam laporan peneltian mahasiswa selalu menggunakan cara manual, mereka menghitung sesuai dengan rumus yang telah dipelajari selama perkuliahan, tidak pernah menggunakan program SPSS".

Wijaya (2011) menjelaskan bahwa SPSS merupakan salah satu perangkat yang dikembangkan pada tahun 1960 sebagai alat bantu perhitungan secara statistik oleh Norman H. Nie, C. Hadlay serta Date Bent dari Stanford University. SPSS mengalami perkembangan dari versi 6.0 hingga versi 23. Pada umumnya SPSS lebih banyak digunakan untuk analisis statistik dalam ilmu-ilmu sosial.

Berdasarkan pernyataan tersebut, maka program SPSS dapat memberikan kemudahan bagi mahasiswa dalam proses analisis data penelitian. Diadakannya pelatihan analisis data instrumen dengan menggunakan program SPSS diharapkan mahasiswa mampu mengoperasikan program SPSS dalam analisis data instrumen. Pelatihan analisis data instrumen ini dikhususkan pada uji coba instrumen penelitian, yaitu analisis uji validitas dan uji reliabilitas. Mengingat langkah utama sebelum melakukan penelitian adalah uji coba instrumen terlebih dahulu, dan program SPSS yang dioperasikan adalah program SPSS Versi 22. Oleh karena itu, kami selaku Tim Dosen Program Studi Pendidikan Sejarah STKIP-PGRI Lubuklinggau bermaksud untuk mengadakan pengabdian dengan judul "Pelatihan Analisis Uji Coba Instrumen dengan Menggunakan Program SPSS Versi 22”.

Pelatihan dengan menggunakan Program SPSS, sebelumnya sudah pernah dilakukan di STKIP-PGRI Lubuklinggau, namun berdasarkan keterangan mahasiswa Program Studi Pendidikan Sejarah, meraka belum pernah mengikuti pelatihan tersebut. Oleh karena mahasiswa belum pernah mengikuti pelatihan untuk mengoperasikan program SPSS, maka Pengabdian Kepada Masyarakat ini perlu untuk dilaksanakan. Dengan tujuan (1) agar mahasiswa dapat memahami analisis uji coba instrumen melalui pelatihan dengan menggunakan SPSS Versi 22; dan (2) agar mahasiswa dapat mengoperasikan program SPSS Versi 22 sebagai alat untuk menganalisis data uji coba instrumen. 


\section{JURNAL CEMERLANG: Pengabdian pada Masyarakat \\ P-ISSN 2654-4741 / E-ISSN 2655-7894 \\ Vol. 3, No. 1, Desember 2020, 29 - 37 \\ DOI: https://doi.org/10.31540/jpm.v3i1.859 \\ PENERBIT: LP4MK STKIP PGRI LUBUKLINGGAU}

\section{METODE}

Metode yang dilakukan pada kegiatan ini dengan dua tahap yaitu tahap persiapan, tahap pelaksanaan dan evaluasi.

Kegiatan Pengabdian Kepada Masyarakat dengan judul "Pelatihan Analisis Uji Coba Instrumen dengan Menggunakan Program SPSS Versi 22" dilaksanakan dengan menggunakan berbagai metode. Adapun metode yang digunakan yaitu metode ceramah, tanya jawab, dan metode demonstrasi. Kegiatan pelatihan ini dilaksanakan pada hari Kamis tanggal 19 Desember 2019 di Ruang Laboratorium Pendidikan Sejarah STKIP-PGRI Lubuklinggau dari pukul 08:00 s.d 17:40 WIB. Sedangkan yang menjadi sasaran dalam kegiatan pelatihan ini adalah mahasiswa yang mengikuti mata kuliah Evaluasi Pembelajaran Sejarah dan mahasiswa yang mengikuti mata kuliah Penelitian Pendidikan sebanyak 27 mahasiswa.

Adapun teknik dalam mengevaluasi kegiatan pengabdian ini yaitu dengan menggunakan observasi dan angket tanggapan peserta terhadap pelaksanaan kegiatan dilihat selama pelaksanaan kegiatan. Sedangkan indikator yang digunakan sebagai ukuran keberhasilan kegiatan yang dilakukan yaitu: (1) peserta mencapai target yang ditetapkan, yaitu 50 peserta yang hadir; (2) antusiasme peserta mengikuti kegiatan dalam kategori baik dengan penentuan kategori baik ini didasarkan pada pendapat Arikunto (2007) yang menyatakan bahwa persentase antara 81\%-100\% sangat baik; $61 \%-80 \%$ baik; $41 \%-60 \%$ cukup; $21 \%-40 \%$ kurang; dan 0\%-20\% kurang sekali; dan (3) mahasiswa yang dapat mengoperasikan program SPSS Versi 22 sebagai alat untuk analisis data uji coba instrumen sebanyak $75 \%$.

\section{HASIL dan PEMBAHASAN}

Kegiatan pelaksanaan Pengabdian Kepada Masyarakat dengan judul "Pelatihan Analisis Uji Coba Instrumen dengan Menggunakan Program SPSS Versi 22" dilaksanakan di Laboratorium Pendidikan Sejarah STKIP-PGRI Lubuklinggau pada hari Kamis tanggal 19 Desember 2019. Kegiatan ini dibuka 


\section{JURNAL CEMERLANG: Pengabdian pada Masyarakat \\ P-ISSN 2654-4741 / E-ISSN 2655-7894 \\ Vol. 3, No. 1, Desember 2020, 29 - 37 \\ DOI: https://doi.org/10.31540/jpm.v3i1.859 \\ PENERBIT: LP4MK STKIP PGRI LUBUKLINGGAU}

oleh Ketua Program Studi Pendidikan Sejarah STKIP-PGRI Lubuklinggau, Ibu Yeni Asmara, M.Pd., dan dihadiri oleh mahasiswa Program Studi Pendidikan Sejarah Semester, I, V, dan VII. Secara umum kegiatan ini berjalan lancar dengan hasil yang cukup memuaskan, terlihat dari hasil evaluasi dari proses kegiatan pelatihan uji coba instrumen dengan menggunakan program SPSS Versi 22. Hasil evaluasi meliputi kehadiran peserta dalam mengikuti kegiatan, antusiasme peserta, tanggapan terhadap pelaksanaan kegiatan, serta kemampuan mahasiswa dalam mengoperasikan program SPSS Versi 22. Hasil penilaian tersebut diuraikan di bawah ini.

Peserta yang diundang dalam kegiatan ini adalah seluruh mahasiswa Program Studi Pendidikan Sejarah STKIP-PGRI Lubuklinggau, semester V dan VII dengan target 50 peserta. Namun, peserta yang hadir dalam kegiatan hanya 29 peserta. Meskipun kehadiran peserta adalah $58 \%$ dari target yang ditetapkan, namun berdasarkan data mahasiswa yang mengikuti mata kuliah Evaluasi Pembelajaran Sejarah dan Penelitian Pendidikan Sejarah sudah mewakili, karena mahasiswa yang mengikuti mata kuliah Evaluasi Pembelajaran Sejarah juga mengikuti mata kuliah Penelitian Pendidikan Sejarah. Dengan demikian, kehadiran peserta bisa dikatakan cukup memuaskan. Selain itu, peserta yang mengikuti pelatihan ini tidak hanya dihadiri oleh mahasiswa semester V (lima) dan VII (tujuh), melainkan juga dihadiri oleh mahasiswa semester I (satu).

Kegiatan pelaksanaan Pengabdian Kepada Masyarakat dengan judul "Pelatihan Analisis Uji Coba Instrumen dengan Menggunakan SPSS Versi 22" diikuti oleh peserta dengan antusiasme yang tinggi. Hal ini terlihat dari perhatian yang ditunjukkan oleh hampir semua peserta, dari awal sampai akhir kegiatan melalui kegiatan observasi. Bahkan, dalam sesi tanya jawab, peserta juga mengajukan pertanyaan-pertanyaan yang menunjukkan antusiasme mereka dan pertanyaan yang diajukan sesuai dengan permasalahaan yang ada dihadapi mahasiswa dalam penyususnan kisi-kisi instrumen dan analisis data uji coba instrumen. Data hasil penilaian terhadap antusiasme peserta dalam mengikuti 


\section{JURNAL CEMERLANG: Pengabdian pada Masyarakat \\ P-ISSN 2654-4741 / E-ISSN 2655-7894 \\ Vol. 3, No. 1, Desember 2020, 29 - 37 \\ DOI: https://doi.org/10.31540/jpm.v3i1.859 \\ PENERBIT: LP4MK STKIP PGRI LUBUKLINGGAU}

kegiatan pelatihan ini dapat ditunjukkan pada Tabel 4.1 sebagai berikut.

Tabel 1

Antusiasme Peserta dalam Mengikuti Kegiatan

\begin{tabular}{|c|c|c|c|c|c|c|c|}
\hline \multirow[b]{2}{*}{ No } & \multirow[b]{2}{*}{ Aspek yang Diamati } & \multicolumn{5}{|c|}{ Nilai } & \multirow[b]{2}{*}{ Jumlah } \\
\hline & & $\begin{array}{l}\text { Sangat } \\
\text { Baik }\end{array}$ & Baik & Cukup & Kurang & $\begin{array}{l}\text { Sangat } \\
\text { Kurang }\end{array}$ & \\
\hline 1 & $\begin{array}{l}\text { Perhatian selama } \\
\text { kegiatan } \\
\text { berlangsung }\end{array}$ & $\sqrt{ }$ & & & & & 5 \\
\hline 2 & $\begin{array}{l}\text { Keterlibatan dalam } \\
\text { tanya jawab }\end{array}$ & & $\sqrt{ }$ & & & & 4 \\
\hline 3 & $\begin{array}{l}\text { Semangat peserta } \\
\text { dalam mengajukan } \\
\text { pertanyaan terkait } \\
\text { materi }\end{array}$ & & & $\sqrt{ }$ & & & 3 \\
\hline 4 & $\begin{array}{l}\text { Kerjasama peserta } \\
\text { selama kegiatan }\end{array}$ & & $\sqrt{ }$ & & & & 4 \\
\hline & & or yang & Dipero & & & & 16 \\
\hline
\end{tabular}

Keterangan: skor 5: sangat baik, skor 4: baik, skor 3: cukup baik, skor 2: kurang baik, skor 1: sangat kurang baik

$$
\text { Persentase }=\frac{\text { Skor yang Diperoleh }}{\text { Skor Maksimal }} \times 100 \%=\frac{16}{20} \times 100 \%=80 \%
$$

Berdasarkan Tabel 1 dan hasil perhitungan persentase di atas, maka secara keseluruhan antusiasme peserta dalam mengikuti kegiatan Pelatihan Analisis Uji Coba Instrumen dengan Menggunakan Program SPSS Versi 22 yang diselenggarakan oleh tim dosen dan mahasiswa STKIP-PGRI Lubuklinggau dapat dikatakan baik. Hal ini sesuai dengan indikator keberhasilan yang telah diitetapkan bahwa persentase 61\%-80\% dikategorikan baik.

Antusiasme peserta dalam mengikuti kegiatan pelatihan ini yaitu bisa dilihat juga dari jumlah mahasiswa yang bertanya. Pertanyaan yang diajukan kepada pemateri terkait dengan materi yang disampaikan dan terkait dengan pengoperasian program SPSS Versi 22. Dari 29 peserta yang mngikuti kegiatan pelatihan terdapat 9 pesrta yang mengajukan pertanyaan: (1) Amelia (mahasiswa semster V); (2) Suminariati (mahasiswa semester V); (3) Getsah Afriweni (mahasiswa semester VII); dan (4) Septia Nuri Anjani (mahasiswa semester VII). 


\section{JURNAL CEMERLANG: Pengabdian pada Masyarakat \\ P-ISSN 2654-4741 / E-ISSN 2655-7894 \\ Vol. 3, No. 1, Desember 2020, 29 - 37 \\ DOI: https://doi.org/10.31540/jpm.v3i1.859 \\ PENERBIT: LP4MK STKIP PGRI LUBUKLINGGAU}

Adapun pertanyaan-pertanyaan yang diajukan yaitu: (1) bagaimana langkahlangkah dalam menyusun instumen penelitian? Pertanyaan ini diajukan oleh Amelia; (2) Mengapa data instrumen penelitian harus valid dan reliabel, dan bagaimana jika data yang diujicobakan tidak valid dan tidak reliabel? Pertanyaan ini diajukan oleh Suminariati; (3) apakah yang menjadi perbedaan menganalisis data uji instrumen dengan menggunakan cara manual dan dengan mengoperasikan program SPSS Versi 22 dan apa bedanya SPSS Versi 6.0 sampai dengan Versi 22? Pertanyaan ini diajukan oleh Getsah Afriweni; (4) Apakah dalam uji validitas dan uji reliabilitas harus menggunakan langkah-langkah yang sama? Maksudnya adalah, jika kita menggunakan cara manual, banyak sekali pilihan dalam analisis uji validitas, dan bagaimana dengan pengolahan data validitas dengan program SPSS? Pertanyaan ini diajukan oleh Septia Nuri Anjani.

Pelaksanaan kegiatan Pelatihan Uji Coba Instrumen dengan menggunakan Program SPSS Versi 22 ini dilakukan dengan cara membentuk kelompokkelompok kecil, di mana kelompok keicil ini terdiri dari 10 kelompok dengan masing-masing kelompok berjumlah 2-3 peserta. Beradasarkan hasil Pelatihan Analisis Uji Coba Instrumen dengan Menggunkan Program SPSS Versi 22, sebagian mahasiswa sudah mampu untuk mengoperasikan program SPSS. Hal ini dilihat pada saat proses latihan menganalisis data instrumen dari data yang sudah diberikan oleh pemateri. Dari 10 kelompok peserta hanya terdapat 8 kelompok peserta yang dapat mengoperasikan program SPSS atau sekitar 80\% mahasiswa mampu mengoperasikan program SPSS Versi 22. Dengan demikian secara umum, mahasiswa mampu mengoperasikan program SPSS Versi 22 dalam analisis uji coba instumen. Dan mahasiswa yang mendapatkan predikat peserta terbaik dalam Pelatihan Analisis Uji Coba Instrumen dengan Menggunakan Program SPSS Versi 22 adalah mahasiswa atas nama Peni dan Suminariati. 

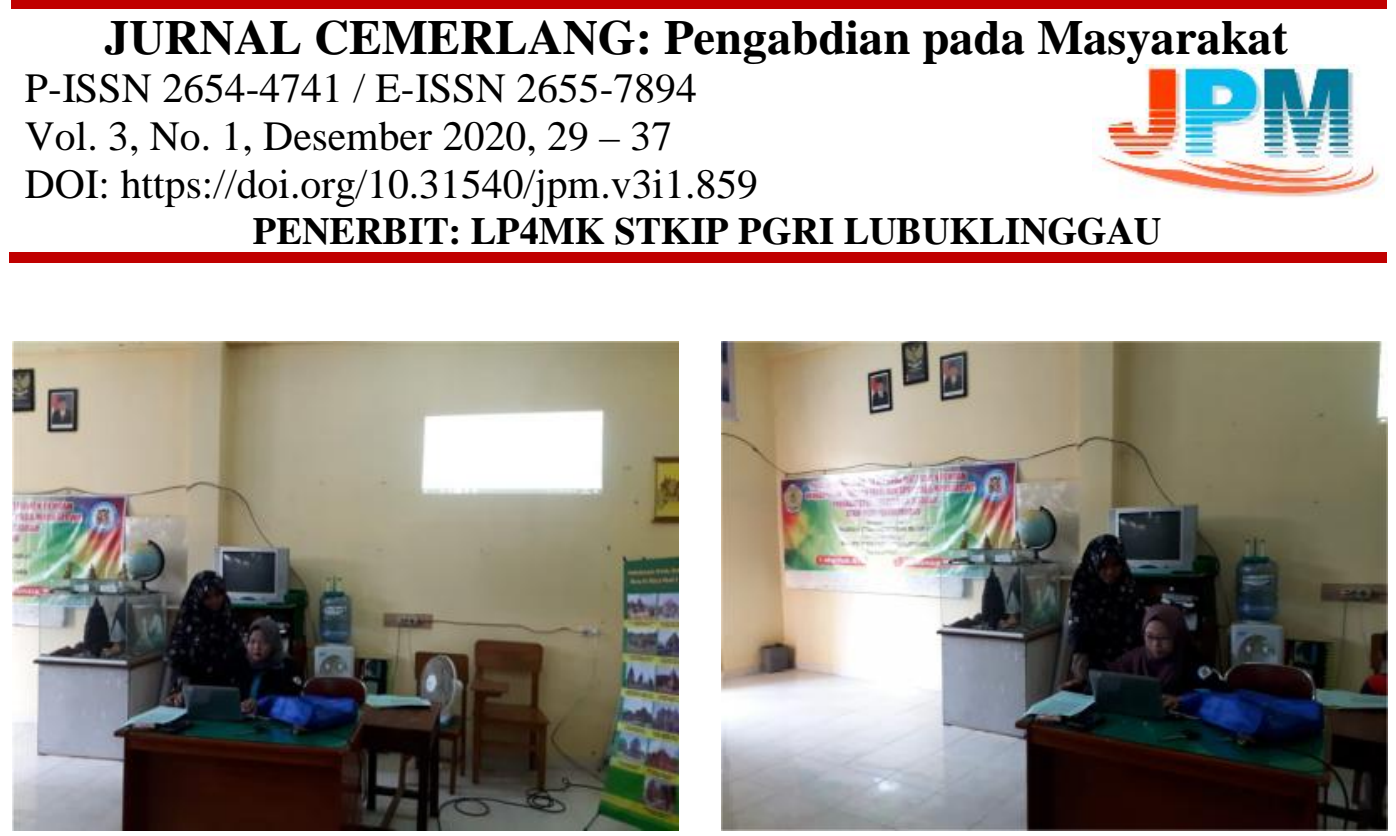

Gambar 1. Salah Satu Peserta Pelatihan Saat Sedang Mengoperasikan Program SPSS Versi 22 (Foto 1 Pemateri dengan Mahasiswa Peni sedangkan Foto 2 Pemateri dengan Mahasiswa Suminariati)

\section{SIMPULAN}

Berdasarkan pembahasan sebelumnya, maka dapat disimpulkan bahwa pelaksanaan kegiatan ini berjalan dengan baik. Hal ini dilihat dari jumlah kehadiran peserta, antusiasme peserta dalam mengikuti proses kegiatan pelatihan, dan mahasiswa mampu mengoperasikan program SPSS Versi 22 sebagai alat untuk menganalisis data uji coba instrumen penelitian dengan baik. Kedepannya, diharapkan kegiatan Pengabdian Kepada Masyarakat dalam bentuk pelatihan ini perlu adanya program kelanjutan agar mahasiswa lebih terampil dan mampu dalam mengoperasikan program SPSS dengan versi yang terbaru sesuai dengan tuntutan perkembangan ilmu pengetahuan dan teknologi, meninggalkan cara-cara tradisional dan menyesuaikan analisis stratistik sesuai dengan kualifikasi ilmunya.

\section{DAFTAR PUSTAKA}

Arikunto, Suharsimi. (2006). Prosedur Penelitian Suatu Pendekatan Praktik. Jakarta: Rineka Cipta.

Muhtadin, M., Satinem, S., Sari, D. D., \& Saputra, S. (2020). Pelatihan dan pendampingan penyusunan bahan ajar bagi guru pondok pesantren mazroillah kota lubuklinggau dalam meningkatkan kualitas pembelajaran. Jurnal cemerlang: Pengabdian pada Masyarakat, 2(2), 162-172. 


\section{JURNAL CEMERLANG: Pengabdian pada Masyarakat}

P-ISSN 2654-4741 / E-ISSN 2655-7894

Vol. 3, No. 1, Desember 2020, 29 - 37

DOI: https://doi.org/10.31540/jpm.v3i1.859

PENERBIT: LP4MK STKIP PGRI LUBUKLINGGAU

Satinem, S., Juwati, J., \& Noermanzah, N. (2020). Developing Teaching Material of Poetry Appreciation Based on Students Competency Analysis. English Review: Journal of English Education, 8(2), 237.

Undang-Undang Nomor 12 Tahun 2012 tentang Pendidikan Tinggi Pasal 45.

Wawancara dengan Ibu Miyarni Sustianingsih, S.Pd., M.Hum. pada tanggal 25 November 2019 di ruang Program Studi Pendidikaan Sejarah

Wijaya, Tony. (2011). Cepat Menguasi SPSS 19. Yogyakarta: Cahaya Atma.

Asmara, Y., Muslihah, N. N., \& Isbandiyah, I. (2019). p pelatihan penulisan aksara ulu sebagai upaya pelestarian budaya daerah pada kelompok musyawarah guru mata pelajaran (mgmp) sejarah kota lubuklinggau. jurnal cemerlang: Pengabdian pada Masyarakat, 1(2), 39-50. 